\title{
An Unusual and Fatal Case of Perthes' Syndrome
}

\author{
F. B. Balde ${ }^{1 *}$, I. Oualili ${ }^{1}$, I. Sidibe ${ }^{2}$, T. Mukenge ${ }^{1}$, A. Mahmoudi ${ }^{1}$, M. Berdai ${ }^{2}$, K. Khatalla ${ }^{1}$, \\ Y. Bouabdallah'1
}

${ }^{1}$ Department of Pediatric Surgery, Hassan II Hospital and University Centre, Fez, Morocco

${ }^{2}$ Mother and Child Resuscitation Service, Hassan II Hospital and University Centre, Fez, Morocco

Email: ^fatoumatabinta.balde@usmba.ac.ma

How to cite this paper: Balde, F.B., Oualil, I., Sidibe, I., Mukenge, T., Mahmoudi, A., Berdai, M., Khatalla, K. and Bouabdallah, Y. (2020) An Unusual and Fatal Case of Perthes' Syndrome. Open Journal of Pediatrics, 10, 515-520.

https://doi.org/10.4236/ojped.2020.103052

Received: July 19, 2020

Accepted: September 8, 2020

Published: September 11, 2020

Copyright $\odot 2020$ by author(s) and Scientific Research Publishing Inc. This work is licensed under the Creative Commons Attribution International License (CC BY 4.0).

http://creativecommons.org/licenses/by/4.0/

\section{Open Access}

\begin{abstract}
Perthes syndrome includes cervical and facial cyanosis, subconjunctival haemorrhage, petechial haemorrhages on the face, neck, and upper chest, secondary to chest compression. We report a clinical case of Perthes' syndrome in 3-year-old boy victims of chest crush by a tractor. Clinical examination found: a Glasgow score at 13/15, polypnea, tachycardia, hypotension; wound of the occipital scalp, a low abundance of hematuria, deformation of the left lower limb. Body scan: bilateral pneumothorax and pulmonary contusions, left hemothorax; lacerations at the medial and upper renal pole grade IV, a low abundance of retroperitoneal hematoma, fracture of the left femur. Biological assessment showed major metabolic disturbances with severe acute rhabdomyolysis and multi-visceral failure. Without clinical improvement, the patient died after 36 hours of intensive care.
\end{abstract}

\section{Keywords}

Perthes Syndrome, Traumatic Asphyxia, Complications, Lethal

\section{Introduction}

The Perthes syndrome is traumatic asphyxia secondary to a crushing to the thoracoabdominal region. It is characterized by a clinical trial of the face and neck cyanosis with oedema, sub-conjunctival haemorrhage and petechial haemorrhages on the face, neck and upper chest. It is traumatic asphyxia also known as Perthes Syndrome [1] [2] [3]. Usually occurs during a work accident, chest compressions during mass movement but in children, road accidents are more common [4]. Treatment is nonspecific and symptomatic [4]. 
We report an unusual and fatal case of Perthes syndrome in a 3-year-old child.

\section{Clinical Description}

3-year-old boy, victims of multiple trauma by compressing a tractor against the wall for a few minutes with the initial loss of consciousness. Received at the university hospital centre of $\mathrm{Fez}$ (CHU) 5 hours after the trauma with a Glasgow score at 13 , blood pressure $100 / 70 \mathrm{mmHg}$, tachycardia (210 beats/min), polypnea $(43 \mathrm{c} / \mathrm{min})$ and pulsed saturation at $90 \%$. Admitted to the intensive care unit of pediatric emergencies, monitoring and resuscitation measures. The clinical examination was marked by a right temporal wound of $4 \mathrm{~cm}$; petechiae of the face and neck, bilateral subconjunctival haemorrhage and epistaxis (Figure 1). He had a low abundance of hematuria; the left lower limb in abduction and external rotation.

Body scan: cerebral level was normal. There was a low abundance of pneumothorax and hemothorax (Figure 2). Multiple lacerations of the left kidney (middle and polar superior) with extravasation of the contrast product (Figure 3 ); and fracture of the left femur (Figure 4).

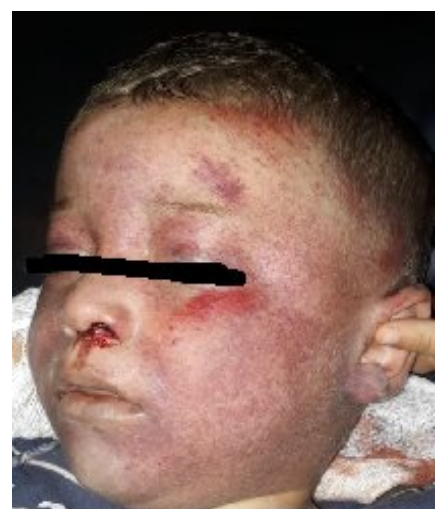

Figure 1. Manifestations cutanées du syndrome de Perthes.

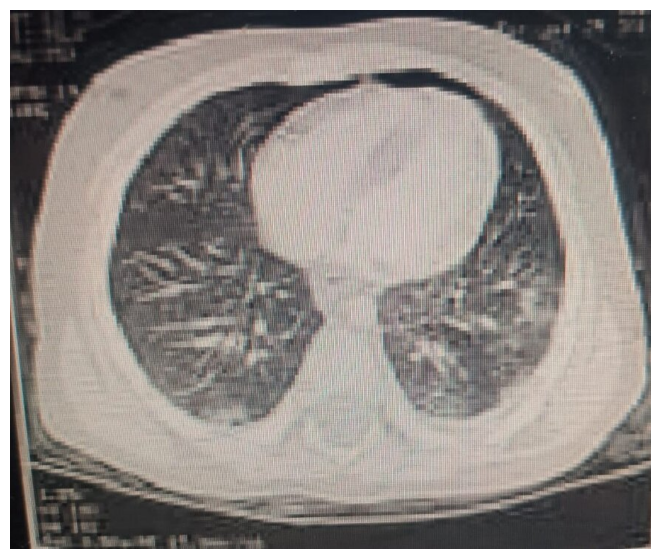

Figure 2. Coupe axiale thoracique du body scan montrant un pneumothorax et hémothorax de faible abondance. 


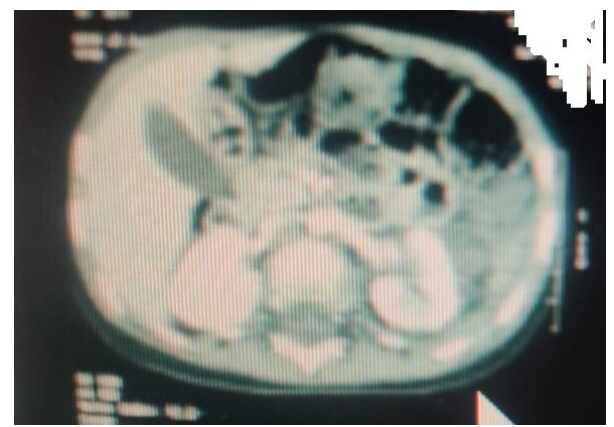

Figure 3. Coupe transverse abdominal du body scan montrantlacération médio polaire rénale gauche avec extravasation de PDC avec un hematoma retro péritonéal de faible abondance.

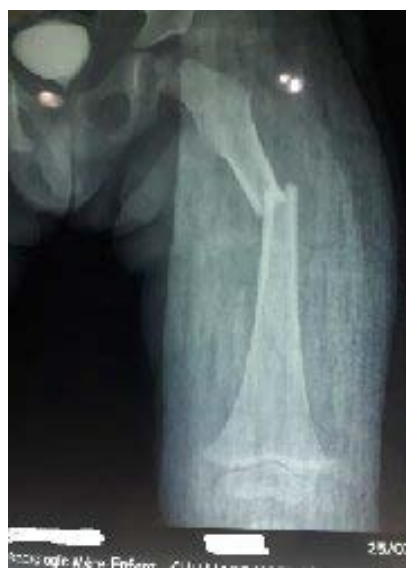

Figure 4. Fracture du femur gauche.

The results of the biological assessment are shown in Table 1. Suture of the wound of the scalp and orthopaedic management of the left femur were performed.

The immediate evolution at 6 hours after his admission to the emergency intensive care was marked by the sudden onset of a fever at $43^{\circ} \mathrm{C}$, restlessness, partial convulsive seizures, altered state of consciousness (Glasgow score 8/15), 23\% desaturation and worsening of the hemodynamic state (PA 60/20 $\mathrm{mmHg}$ ).

He was intubated, ventilated, sedated and put on vasoactive drugs. The onset of precarious stability (tight myosis bilaterally with slight hemodynamic improvement).

Biological and morphological exploration carried out urgently objectifying: haemorrhage (haemoglobin from $9 \mathrm{~g} / \mathrm{dl}$ to $6 \mathrm{~g} / \mathrm{dl}$ ), low platelet rate, and alteration of the hemostasis assessment with a low prothrombin rate.

Administration of blood products ( 1 red blood cell consent, 2 platelet consent and 2 fresh frozen plasma) with an improvement at biological control (Table 1). Cerebral control CT scan no abnormality has been detected, and lesions were stable at the abdominal ultrasound. Chest X-ray (images of low abundance of bilateral pneumothorax, atelectasis, and condensation). 
Table 1. Biological assessment of the patient during the first 48 hours.

\begin{tabular}{ccc}
\hline & 24 hours & 36 hours \\
\hline Hemoglobin level (mg/dl) & 6.50 & 15.20 \\
Hematocrit (\%) & 14 & 45 \\
Platelets/uL & 34,000 & 808,000 \\
Alkaline reserve mmol/L & 9 & 4.7 \\
Potassium mEq/L & 5.9 & \\
CPK UI/L & 3995 & \\
CPK MB UI/L & 193 & \\
TCA (second) & 49.80 & \\
TP (\%) & 32.90 & \\
INR & 1,90 & \\
Lipase UI/L & 226 & \\
LDH UI/L & 3325 & \\
GPT UI/L & 1619.0 & \\
GOT UI/L & 993 & \\
Urea g/L & 1.11 & \\
Creatinine mg/L & 15 & \\
\hline
\end{tabular}

In the first 24 hours of hospitalization, he presented an abolition of brainstem reflexes (probable brain death) not explored by medical imaging. In conclusion, the evolution was marked by the complications of severe and acute rhabdomyolysis leading to multi-visceral failure: neurological, hemodynamic, respiratory, hematologic, renal, hepatic. Then at 36 hours of his admission, the patient died by cardiorespiratory arrest not recovered by the resuscitation measures. The autopsy on the body was not performed.

\section{Discussion}

The occurrence of Perthes syndrome is rare with an incidence of 1 case in 18,500 accidents [2]. Our case is in addition to the 4 cases described for 6 years in the pediatric surgery department of CHU Hassan II in Fez [3]. The patient was a victim of a work accident, an unusual cause for this age group where accidents on the public highway are mainly reported [4]. Whatever the cause, there is always a phenomenon of chest compression and the presence of the classic triad [5] [6] [7]. The physiopathological mechanism deduced by Perthes seems to be applicable whatever the aetiology. The victim perceives the onset of the trauma which triggers a fear reaction consisting of blocking the thorax in forced inspiration with the glottis closed. This increases the pressure in the superior vena cava, causing venous reflux with rupture of the capillary venules in the drainage areas of the SVC responsible for the characteristic petechial and subconjunctival hae- 
morrhages as described in the observation section of the patient [2] [8].

Neurological manifestations are common (90\%) and lead to disturbances of consciousness, including deep coma [5] [8]. Neurological manifestations result from cerebral anoxia resulting from reduced cerebral blood flow and or direct injury from cranial impact. In our patient, the neurological complications were severe. From drowsiness, the evolution took place towards a state of agitation with convulsive crises replaced by coma. This neurological manifestation could be due to secondary cerebral aggression of systemic origin.

The patient presented with major metabolic disorders: severe acute rhabdomyolysis, hyperkalaemia, metabolic acidosis, acute renal failure and hepatic cytolysis.

The trauma causes muscle crushing and the release of intracellular potassium responsible for hyperkalaemia. Metabolic acidosis is secondary to the release of lactic acid [9] [10] [11]. Muscle cells contain a high concentration of myoglobin which enters the circulation during rhabdomyolysis. The kidneys filter myoglobin and excrete it in the urine. High levels of urinary myoglobin damage the kidneys and lead to acute kidney failure. Enzymes released by damaged muscle cells can trigger inflammation of the liver which results in an increase in other enzymes LDH, GPT, GOT; resulting in hepatic dysfunction [9] [10] [11].

Hyperpyrexia is a final stage of hyperthermia where the body is no longer able to thermoregulate and sustains rhabdomyolysis.

The patient had no brain damage to CT. Out of 8 fatal cases of Perthes syndrome recorded in Department of Surgery at the University of Rochester Medical Centre, no case had a lesion detectable on CT [2]. Bilateral pneumothorax and left hemothorax were in low abundance and warranted no surgical management. The patient was polytrauma patients with multiple impact points. That explains the other associated retroperitoneal lesions and the femoral fracture.

Treatment is nonspecific and symptomatic on a case-by-case basis [4].

Usually, the neurological manifestations disappear within 24 to 48 hours with early and appropriate treatment. Then the prognosis will depend on the ocular function [6]. The poor result, in this case, can be explained by the long delay in treatment, the severe metabolic disturbances which, for each other, constitute a life-threatening vicious circle.

\section{Conclusion}

Perthes syndrome is not entirely benign. The vital prognosis depends on the one hand on the duration of the compression mechanism, on the precocity of adequate treatment and on the other hand, on the severity of the associated lesions. The tolerance of traumatic asphyxia must be analyzed in a particular way in children.

\section{Ethics Aspects}

The parents have already given their consent to use the kid's data to write and 
publish a scientific work.

\section{Author Contribution}

All authors contributed to the writing of the work and approved the final version.

\section{Conflicts of Interest}

The authors declare no conflicts of interest regarding the publication of this paper.

\section{References}

[1] Richards, C.E. and Wallis, D.N. (2005) Asphyxiation: A Review. Trauma, 7, 37-45. https://doi.org/10.1191/1460408605ta330oa

[2] Barakat, M., Belkhadir, Z.H., Belkrezia, R., Faroudy, M., Ababou, A., Lazreq, C. and Sbihi, A. (2004) Syndrome d'asphyxie traumatique ou syndrome de Perthes. À propos de six cas. Annales Françaises d Anesthésie et de Réanimation, 23, 59-62. https://doi.org/10.1016/j.annfar.2003.10.011

[3] Rabhi, H. (2008) Syndrome de Perthes ou traumatisme asphyxique chez l'enfant (à propos de 4 cas). Thèse, Faculté de médecine et de pharmacie de Fès-Maroc, 36-08.

[4] Fitouri, F., Sahli, S., Houas, Y., Sassi, N. and Hamzaoui, M. (2017) Perthes Syndrome: A Pediatric Case. Acta Angiologica, 23, 163-164.

https://doi.org/10.5603/AA.2017.0017

[5] Jobé, J., Ghuysen, A., Hartstein, G. and D’orio, V. (2013) A Fatal Case of Perthes Syndrome. Journal of Emergencies, Trauma, and Shock, 6, 296-297. https://doi.org/10.4103/0974-2700.120385

[6] Mazocky, E., Vallé, B. and Biais, M. (2013) Perthe's Syndrome or Traumatic Asphyxia. Annales françaises de médecine durgence, 3, 117. https://doi.org/10.1007/s13341-013-0278-6

[7] Karamustafaoglu, Y.A., Yavasman, I., Tiryaki, S. and Yoruk, Y. (2010) Traumatic Asphyxia. International Journal of Emergency Medicine, 3, 379-380. https://doi.org/10.1007/s12245-010-0204-x

[8] Sedik, A.M. and Elhoushy, S. (2017) Traumatic Asphyxia: A Case Report and Literature Review. Saudi Surgical Journal, 5, 84-86. https://doi.org/10.4103/ssj.ssj_80_16

[9] Jongewaard, W.R., Cogbill, T.H. and Landercasper, J. (1992) Neurologic Consequences of Traumatic Asphyxia. The Journal of Trauma, 32, 28-31. https://doi.org/10.1097/00005373-199201000-00006

[10] Lewandowsk, K.B. (1981) Rhabdomyolysis, Myoglobinuria and Hyperpyrexia Caused by Suxamethonium in a Child with Increased Creatine Kinase Concentrations. British Journal of Anaesthesia, 53, 981-984. https://doi.org/10.1093/bja/53.9.981

[11] http://univ.ency-education.com/uploads/1/3/1/0/13102001/physiopath27-dyskaliem ies.pdf 